\title{
DIVULGAÇÃO EM DEMONSTRAÇÕES FINANCEIRAS DE COMPANHIAS ABERTAS
}

Autor: Eduardo Falcão

Mestre em Controladoria e Contabilidade pela FEA/USP

A forma pela qual uma empresa comunica o seu desempenho aos usuários externos através das demonstrações financeiras pode significar o sucesso ou o fracasso quando em um determinado momento surja a necessidade de obter recursos junto a seus acionistas, investidores ou outras empresas interessadas apenas em manter um relacionamento comercial.

Apesar do progresso significativo no Brasil deste tipo de divulgação de informações por companhias abertas nos últimos 40 anos, entendemos serem ainda necessárias maior clareza e objetividade, especialmente no que concerne ao Relatório da Administração, através do qual os administradores prestam contas sobre os recursos colocados à sua disposição pelos acionistas.

Usuários externos e, cada vez mais, a sociedade como um todo, necessitam informações acuradas para que possam tomar as melhores decisões ou avaliar o resultado do uso dos recursos da sociedade administrados pelas empresas.

A partir desta análise desenvolvemos um trabalho de pesquisa, cujo resumo é apresentado a seguir, com o objetivo de detectar o nível de atendimento das recomendações legais por parte das companhias abertas do ramo industrial, em termos de divulgações nas demonstrações financeiras publicadas.

\section{Conceito de Divulgação e Objetivos da Contabilidade}

A divulgação no conjunto deste trabalho deve ser entendida como o meio pelo qual os diversos usuários das demonstrações financeiras (clientes, fornecedores, empregados, governo, analistas etc.), obtêm conhecimento do atual estágio de um determinado empreendimento econômico, tanto em termos de situação patrimonial e financeira, como de lucratividade e aplicações dos recursos disponíveis, tomando por base um período estabelecido.

O entendimento do momento em curso, aliado à análise do momento pretérito, deverá conduzir o usuário a ajudar a inferir sobre o futuro da entidade, pois a partir desta expectativa futura será tomada a decisão de investir ou não nos recursos em determinada atividade econômica. Possibilitará, também, a avaliação de desempenho dos gestores dos recursos, o estabelecimento do nível de emprego, negociações salariais, transações comerciais etc.

Entretanto para esse entendimento faz-se necessária uma forma adequada de transmitir as informações contábeis, as quais devem refletir com a máxima fidelidade o desempenho operacional da empresa em todos os seus importantes aspectos econômico-financeiros, gerando elementos suficientes para a análise e tomada de decisão por parte dos usuários, pois a Contabilidade vista como um fim em si mesma é um instrumento sem qualquer representatividade no contexto empresarial moderno.

\section{Pontos Referenciais da Divulgação}

$\mathrm{Na}$ análise de demonstrações financeiras dos últimos 30 anos, identificamos três grandes marcos relativamente à evolução da evidenciação no Brasil, quais sejam:

Caderno de Estudos nº12, São Paulo, FIPECAFI, Setembro/1995 
- $\quad$ em 1972 através da Resolução No. 220 e da Circular No. 179 do Banco Central do Brasil, quando foi procedida uma total reformulação da apresentação das demonstrações financeiras.

- em 1977/78 pela emissão da Lei das Sociedades Anônimas, sendo acrescentadas/modificadas algumas demonstrações financeiras, bem como passando-se a dar maior ênfase às notas explicativas e,

- $\quad$ em 1987, através da Instrução № 64 da Comissão de Valores Mobiliários, que introduziu a correção monetária integral sob a forma de demonstrações complementares.

\section{Atual Legislação Brasileira}

\section{Lei das Sociedades Anônimas (№ 6.404/76)}

A Lei das S.A. teve como característica à época de sua emissão um considerável avanço a nível de regulamentação das sociedades por ações, inclusive no que se refere ao "disclosure" em demonstrações financeiras, adequando-as ao processo de desenvolvimento então experimentado pelo país.

Em nosso entender, porém, o seu texto desce a detalhes técnicos desnecessários como conteúdo de uma lei. Para alguns profissionais torna-se mais confortável, por considerar como válido somente o que está ali determinado, enveredando por caminhos jurídicos e não propriamente técnicos contábeis. Infelizmente teremos que conviver com desvios desta natureza, até que todos os profissionais de Contabilidade passem a discussão para o campo econômico-financeiro, estreitamente vinculado à nossa área de atuação, em vez de aspectos legais, que representam o suporte jurídico para as transações e não para a teoria contábil.

Podemos exemplificar, citando o artigo da lei que trata da demonstração de resultado, o qual apesar de ser bastante detalhada, não significa uma limitação aos profissionais sobre aquilo que eles julguem a melhor forma de apresentar as informações.

A legislação, ao indicar uma determinada estrutura, não impede que esta demonstração seja divulgada de forma diferente, desde que isto contribua para a evolução do nível de divulgação. A indicação, na lei, dos títulos Custo de Vendas, Despesas Administrativas, Vendas etc,. não significa a obrigatoriedade de apresentálos "fechados", sem a demonstração dos principais componentes de cada um desses itens.

Todavia o que se contasta é uma demonstração-padrão por parte das empresas, sem qualquer rasgo de responsabilidade para o aperfeiçoamento da evidenciação em nosso país, como ser a lei fosse um obstáculo, o que não é verdade, pois, por mais detalhada que seja, não cabe a ela abarcar todos os aspectos técnicoconceituais.

Somos de opinião de que o detalhamento técnico -contábil em urna lei é um verdadeiro absurdo, pois é como se existisse uma lei que procurasse regulamentar técnicas cirúrgicas na área da Medicina, ou de cálculos estruturais em Engenharia, limitando quaisquer outras incursões científicas que representem maior desenvolvimento tecnológico e conseqüentemente maior bem-estar da sociedade. Ou será que existe uma lei que regule a hermenêutica?

Talvez a Contabilidade seja no Brasil a única profissão que detalhe técnicas operacionais através de lei, provavelmente pela estreita ligação entre a Contabilidade e os interesses a nível fiscal, que necessitam de um maior respaldo jurídico para serem implementados. Entretanto, entendemos que os aspectos jurídicos devem competir aos profissionais do Direito que levando para a prática, julgam, rio caso da Contabilidade pendências 
de caráter técnico utilizando-se de parecer de peritos que tenham informação contábil para fornecer-lhes os subsídios necessários.

Por outro lado, é interessante notar que no caso especifico do artigo 177, onde é mencionado que "a companhia observará em registros auxiliares, sem modificação da escrituração mercantil e das demonstrações reguladas nesta lei, as disposições da lei tributária, ou de legislação especial...", ocorre justamente o contrário daquilo que acabamos de mencionar.

É uma situação peculiar, pois a lei claramente segrega quaisquer efeitos de natureza fiscal ou outra regulamentação especifica para determinadas empresas para efeito de divulgação das demonstrações contábeis. Porém, na prática isto não acontece, em função da legislação fiscal ter poderes (???) para desconsiderar o que é claramente expresso na Lei No. 6.404, tornando compulsório o registro contábil para efeito de benefício fiscal.

Entendemos que o contador consciente de sua responsabilidade perante a sociedade, deve procurar demonstrar o desempenho da empresa segundo normas técnicas emanadas da teoria contábil, não ficando apegado a textos fiscais, mas sim procurando dar lhes a melhor interpretação para atingir os objetivos de sua profissão.

\section{Comissão de Valores Mobiliários (CVM)}

A CVM teve também importante papel na regulação "disclosure" no Brasil, em especial pela instrução CVM № 64/87, com o objetivo de resgatar o valor informativo das demonstrações financeiras, exigindo das companhias abertas demonstrações complementares elaboradas em moeda de poder aquisitivo constante, nas quais os efeitos da inflação são reconhecidos em seus itens de origem.

Nossas demonstrações financeiras conviveram, no período de 1980 a 1985, com índices de inflação de "apenas" 100 a 200\% ao ano, em uma concepção que não levava em consideração o efeito inflacionário sobre os diversos componentes do balanço e da demonstração de resultado.

Neste período, através da conta Correção Monetária de Balanço, muitos desempenhos sofríveis em termos de administração dos recursos das empresas eram justificados pelo efeito global desta conta na demonstração de resultado. Quando na linha anterior à Correção Monetária apresentava-se um lucro que em seguida esta conta transformava em prejuízo, alegava-se que "deu prejuízo somente por causa da conta de Correção Monetária" e, como ninguém entendia o seu real significado (da mesma maneira que nunca se explicou a conta "Translation Gain/Loss" nas demonstrações em moeda estrangeira), aceitava-se amplamente tal justificativa.

Com o sistema de Correção Integral foi eliminada esta perversa conta "que causou tantos prejuízos" a algumas empresas, alocando-se os efeitos inflacionários aos seus diversos componentes e explicando exatamente a origem daqueles prejuízos, que na verdade eram puramente de caráter operacional e não um valor surgido ao acaso ou um "mero ajuste contábil" (como alguns gostam de se referir a algo cujo conceito não têm pleno domínio).

Este sistema introduziu basicamente dois novos conceitos, quais sejam, a distinção no balanço entre itens monetários e não-monetários, além de ganhos e perdas alocados na demonstração de resultado.

A partir daí, transformou-se radicalmente o conteúdo informativo de nossas demonstrações financeiras, possibilitando novamente a sua utilização para uma correta análise de desempenho, isto é, utilizando uma moeda estável, mesmo convivendo com elevadas taxas de inflação.

Como este método independe da moeda com a qual se queira trabalhar (UMC, dólar, marco, libra etc.), já existem empresas multinacionais utilizando-o para reportar seus resultados aos acionistas no exterior, em razão das vantagens apresentadas em relação ao método de conversão em moeda estrangeira até então

Caderno de Estudos nº12, São Paulo, FIPECAFI, Setembro/1995 
adotado.

Em 1989, a ONU (grupo de trabalho de especialistas em padrões internacionais de Contabilidade e relatórios contábeis) aprovou o nosso sistema de Correção Integral para utilização por empresas transnacionais em países com altos níveis de inflação, como veremos mais adiante.

\section{Pronunciamentos no Exterior}

Com o objetivo de avaliar nosso estágio de divulgação em relação a centros avançados em matéria contábil, analisamos pronunciamentos de alguns órgãos internacionais, a seguir detalhados.

\section{O.N.U. (grupo de trabalho já citado)}

\section{Substância Sobre a Forma}

Nas conclusões estabelecidas em 1988, enfatiza-se a importância a ser dada no que concerne à substância econômica do evento, mesmo que sua forma jurídica apresente-se de maneira diversa da substância econômica e possa sugerir um tratamento diferente.

Evidentemente, as transações econômicas devem ser refletidas da maneira como elas impactarão econômico-financeiramente o desempenho da empresa e não como ela poderia ser registrada contabilmente utilizando algum artifício jurídico visando eventual benefício de ordem fiscal ou outro qualquer.

$\mathrm{Na}$ verdade, tal malabarismo simplesmente compromete as decisões gerenciais. criando controles alternativos para restabelecimento dos números reais, somente conhecidos pelos administradores. Porém, os problemas gerados por contabilizações que não consideram a substância econômica da operação são simplesmente postergados, vindo a aflorar em determinado momento no futuro, dependendo exclusivamente do período contratual da transação.

\section{Imobilizado}

Naquele mesmo ano, o grupo de trabalho concluiu sobre a necessidade de estabelecer-se um critério adequado de depreciação dos bens do imobilizado, qual seja aquele que melhor reflita o fato técnico-econômico, considerando a vida útil-econômica do bem pois, desta maneira, o confronto da receita por ele produzida com a despesa proveniente de sua utilização se faz de maneira adequada.

Concluiu-se também sobre a necessidade de revisão periódica das taxas utilizadas para depreciar os bens, ajustando-as para refletir estimativas mais recentes de expectativa de vida útil.

No Brasil, o principio da essência sobre a forma, neste assunto em particular, é completamente abandonado para dar lugar ao desgaste fiscal, ou seja, à utilização de taxas pré-determinadas pela legislação do imposto de renda para fins de dedutibilidade, sem qualquer consideração ao efetivo desgaste físico ou obsolescência do bem a partir de estudos técnicos de engenharia, para efeito de melhor evidenciação.

Outro aspecto interessante mencionado nestas conclusões diz respeito a contratos para futuros gastos com imobilizado. Estes contratos devem ser quantificados e divulgados. Normalmente não se dá a devida atenção a este tipo de "disclosure" que, entretanto, é de fundamental importância em termos de análise sobre as perspectivas da empresa em sua área de atuação.

Caderno de Estudos nº12, São Paulo, FIPECAFI, Setembro/1995 


\section{Salários}

$\mathrm{Na}$ demonstração de resultado, os diferentes componentes dos custos com a mão-de-obra devem ser divulgados separadamente, a saber:

- salários e pagamentos similares, incluindo o valor de horas-extras;

- custos de pensão;

- custos de outros benefícios pagos a empregados.

No Brasil, esses itens não são visíveis, integrando três grandes grupos que englobam uma série de itens importantes para análise: Custo dos Produtos Vendidos, Despesas Administrativas e Despesas de Vendas.

O Custo dos Produtos Vendidos em termos de evidenciação é, em nossa opinião, uma das maiores aberrações, pois enquanto se discute se a Contribuição Social deve ou não ser destacada e classificada em determinado grupamento da demonstração de resultado, ou o melhor percentual para determinar o valor a ser demonstrado como "outros", a despesa mais importante da demonstração de resultado numa indústria continua sendo evidenciada como um único valor, impossibilitando uma análise mais acurada da evolução de cada componente de custos da companhia.

Pode-se alegar, para tal, a confidencialidade da composição de custos, porém, cada vez mais, através de sindicatos e outros órgãos fiscalizadores, esta exposição deverá se tornar imperativa. E em regime de livre concorrência, e competitividade efetiva, não deverá ser a divulgação da estrutura de custos o fator restritivo para a obtenção de lucratividade adequada, mas sim a competência na condução dos negócios, aliada ao fator fundamental que é a qualidade e aceitação do produto.

\section{Divulgação dos Efeitos Inflacionários}

Conforme antes citado, em 1989 o grupo de trabalho da O.N.U. aprovou o método de Correção Integral adotado no Brasil para empresas transnacionais em países com elevado nível inflacionário (100\% em três anos consecutivos).

Como a inflação passou a ser componente constante em diversas economias no mundo, e mesmo países desenvolvidos não estão imunes a ela, faz-se necessário resgatar o valor informativo das demonstrações financeiras, sem que o usuário necessite efetuar cálculos com base em índices médios de variação de preços ou de variação cambial, mesmo assim sujeitos a grandes distorções em função de peculiaridades operacionais.

Através de um processo relativamente simples como o da Correção Integral, torna-se viável retomar a importância das demonstrações financeiras, agora também a nível internacional.

É importante notar-se que alguns conceitos dela oriundos passaram a influenciar o processo de elaboração de relatórios em "moeda estrangeira".

Primeiramente, "descobriu-se" que o valor em geral mais relevante na demonstração de resultado o denominado "translation gain/loss" poderia ser desmembrado e alocado pelos diversos componentes desta demonstração, a semelhança do tem "ganhos/perdas sobre itens monetários não remunerados".

Antes, aquele item constituía-se em um solene desconhecido, ou melhor, um conhecido que incomodava e cuja única resposta para o seu valor expressivo era sempre a de que nossa moeda apresentava grande desvalorização frente à moeda estrangeira sendo reportada.

Efetivamente, este item representa única e exclusivamente o quanto se ganhou ou perdeu financeiramente através da administração dos ativos e passivos da companhia expostos aos efeitos, quer seja do nível de inflação interno como da variação cambial em relação a moedas estrangeiras.

Caderno de Estudos nº12, São Paulo, FIPECAFI, Setembro/1995 
Outro item que passou a integrar as demonstrações financeiras convertidas para moeda estrangeira ,foi o ajuste a valor presente de créditos e obrigações de valores pré-fixados, em cujo cálculo são utilizadas taxas de juros praticadas pelo mercado financeiro que, em última análise, representam um tipo de custo de oportunidade para aplicação do dinheiro

\section{IASC (International Accounting Standards Committee)}

Destacamos a seguir algumas Normas Internacionais de Contabilidade emitidas por este organismo que objetiva homogeneizar práticas e divulgações contábeis em diversos países.

\section{Divulgação de Práticas Contábeis}

Somente no caso de uma prática contábil não ter uma aceitação generalizada, ela deve ser divulgada.

Consideramos a divulgação dessas práticas já certas como informações que apenas tornam a leitura dos relatórios extremamente cansativa. Ao elaborar-se tais demonstrações, pressupõe-se que o usuário tenha um mínimo de conhecimento de aspectos contábeis.

\section{Imobilizado}

A norma relativa ao imobilizado requer, dentre outras, a divulgação da reconciliação dos valores do imobilizado no início e no fim do período contábil, mostrando adições, vendas, aquisições por meio de Incorporações, fusões e outras transações.

Em nosso país não é comum apresentar a movimentação destas contas, entretanto, parece-nos válida esta evidenciação pois, em sendo um item em geral relevante, deve-se demonstrar em detalhes a sua evolução no período.

Outro item que merece destaque, em especial nos momentos em que o país depara-se com processos econômicos recessivos, é o relativo à divulgação dos bens do imobilizado temporariamente sem utilização. Esta informação pode ser de grande importância para efeito de análise da capacidade ociosa da entidade, comparativamente a outras empresas atuantes no mesmo segmento econômico.

\section{F.A.S.B. (Financial Accounting Standards Board)}

O FASB, como órgão normatizador contábil nos Estados Unidos, está atualmente envolvido na discussão de dois grandes temas:

a) o princípio do "full disclosure" versus o SAR (Summary Annual Report); e

b) os denominados "off balance-sheet".

\section{O princípio do "full disclosure"}

Este princípio, em vigor nos E.U.A., tem como premissa básica a divulgação nas demonstrações financeiras de quaisquer eventos suficientemente significativos para influir no julgamento de um usuário.

Alguns especialistas questionam a validade da evidenciação de maneira tão detalhada e em grande 
quantidade, o que causaria algum grau de dificuldade por parte do usuário para absorver tanta informação. Eles vão além, dizendo que o "full disclosure" não serviu como alerta para algumas empresas com desempenho desastroso em períodos subseqüentes.

Como curiosidade, nos últimos 10 anos, o número médio de páginas de notas explicativas, numa amostra de 10 dentre as maiores empresas norte-americanas, passou de 2,5 para 8,5, enquanto as demais demonstrações contábeis atingiram 17 páginas em média, contra 7 anteriormente.

\section{Summary Annual Report (SAR)}

A quantidade e complexidade das informações exigidas pela SEC (Security and Exchange Comission resultaram em um excesso de informações, as quais são de pouco interesse para a média dos usuários, segundo pesquisa realizada nos Estados Unidos. O SAR apresenta as demonstrações financeiras em um formato mais simples do que o relatório anual tradicional. A sua abordagem baseia-se no conceito de "disclosure" diferenciado, ou seja, alguns usuários têm necessidade de informações no formato de "full disclosure", entretanto, muitos outros necessitam tão somente de um quadro demonstrativo de informações financeiras bastante sumariado e menos técnico.

A idéia básica deste relatório é de que ele não serviria como substituto do relatório anual tradicional. o que ficaria disponível para os usuários que desejassem um volume de informações maior, mas sim ele seria o instrumento de comunicação com a maior parte dos usuários.

Sob nosso ponto de vista, é uma maneira bastante adequada a divulgação de um modelo simplificado para uma análise mais global da empresa por parte da maioria dos usuários, abordando somente alguns pontoschave das demonstrações financeiras, inclusive com a evidenciação de alguns índices de avaliação de desempenho no período sendo reportado, tornando o processo de divulgação a nível geral mais simples.

Off-Balance-Sheet

Outro item em evidência nos Estados Unidos quanto ao "disclosure" é o denominado "off-batance-sheet", isto é, operações contratadas cujo registro contábil não foi efetuado

Algumas transações comerciais foram detectadas como geradoras de "off-batance-sheet", tais como contratos futuros, derivativos, financiamentos para projetos de formação de empresas.

Com o objetivo de minimizar essas práticas, o FASB tem requerido cada vez mais evidenciação,. o que indica que a questão importante é se tais itens são ou não divulgados, em vez de são ou não registrados contabilmente.

No Brasil, o "leasing" é um exemplo clássico de "oft-balance-sheet". Operações cuja essência econômica caracteriza-se como arrendamento do tipo "financeiro não são refletidas contabilmente com o devido registro da dívida e conseqüente contrapartida no imobilizado, em razão de benefícios fiscais".

O critério adotado é totalmente inadequado, não refletindo o desempenho econômico da companhia sendo analisada, cujas distorções somente são conhecidas pelos seus administradores, que necessitam conhecer a real posição do empreendimento.

\section{Pesquisa em Demonstrações Financeiras no Brasil}

\section{Relatório da Administração}

Para avaliação dos Relatórios da Administração publicados, realizamos uma comparação com o disposto no Parecer de Orientação No. 15/87 da Comissão de Valores Mobiliários, quando este órgão pronunciou-se pela primeira vez de forma abrangente sobre o relatório anual dos administradores

Caderno de Estudos nº12, São Paulo, FIPECAFI, Setembro/1995 
Divulgação em Demonstrações Financeiras de Companhias Abertas 8

Com base neste comparativo, constatamos os seguintes principais aspectos.

O maior índice de respostas positivas foi para o item sobre "Comentários sobre a conjuntura econômica geral', enquanto o menor está sendo refletido no item "Proteção ao meio ambiente"

$\mathrm{Na}$ análise destes dois extremos, o grande número de respostas positivas do primeiro deve-se ao fato desta análise ser bastante genérica e de alguma forma imputar ao ambiente externo determinadas causas de um eventual desempenho insuficiente no ambiente interno da empresa, sem o compromisso de provar as assertivas apresentadas. Desta forma, este item aborda algumas análises detalhadas sobre a economia do país, em especial nos períodos de mudança de governantes ou de alterações significativas nas diretrizes gerais de política econômica.

Por outro lado, o pequeno número de respostas positivas para o item "meio ambiente" reflete um aspecto cultural de nosso país, onde a importância da proteção ao meio ambiente ainda não vem tendo a devida atenção por parte das empresas, ou quando isto é feito, esta informação não vem sendo divulgada de forma adequada.

Já os itens relativos a "recursos humanos" e "direitos dos acionistas e dados do mercado" carecem de uma melhor divulgação, conforme sugere o referido Parecer de Orientação.

As informações sobre os recursos humanos das companhias são bastante reduzidas, sendo normalmente mencionados os benefícios concedidos aos empregados, sem entretanto fazer menção ao seu valor total nem ao número de pessoas contratadas, "turnover" etc.

No que concerne ao item "direitos dos acionistas ", as minguadas informações nele apresentadas justificam a insipiência de nosso mercado de valores mobiliários, onde a atuação dos investidores tem um sentido mais especulativo do que propriamente técnico sobre o desempenho das companhias, a liquidez de seus títulos, o retorno proporcionado pelos dividendos etc.

Em termos gerais, o índice de atendimento ao citado Parecer foi muito baixo quanto aos requisitos mínimos de informações a serem prestadas através do Relatório da Administração.

Desta forma, passamos a considerar algumas indagações sobre o atual estágio da divulgação no que concerne a este relatório, quais sejam:

- as pessoas encarregadas de elaborá-lo estão devidamente preparadas para tal?

- se estão, por que as empresas não divulgam objetivamente os fatores que contribuíram para o seu desempenho, sejam eles positivos ou negativos?

- por que os usuários das informações não pressionam de alguma forma para a melhoria de qualidade das informações apresentadas?

- estariam eles satisfeitos com o que lhes vem sendo apresentado?

- as análises efetuadas com base nos dados hoje disponíveis para o público em geral, podem ser consideradas satisfatórias para suportar uma decisão de investimento?

- existe a exata consciência do investidor sobre o seu direito de exigir uma prestação de contas adequada sobre a gestão dos recursos colocados por ele à disposição dos administradores para obter o retorno desejado em termos de juros sobre o seu capital?

- por que o órgão fiscalizador, no caso a Comissão de Valores Mobiliários, não faz cumprir aquilo que ele mesmo recomendou às companhias abertas como forma de melhorar a qualidade das informações dos administradores?

Caderno de Estudos nº12, São Paulo, FIPECAFI, Setembro/1995 
- deveria o Relatório da Administração ser de alguma forma validado pelos Auditores Independentes, visto que o seu conteúdo deve refletir de uma forma sintética e em uma linguagem objetiva e clara os números apresentados nas demonstrações financeiras?

\section{Notas Explicativas}

Procuramos identificar em nosso trabalho alguns aspectos interessantes relativos às notas explicativas às demonstrações financeiras.

\section{Detalhamento de Contas}

Primeiramente, o detalhamento do conteúdo de uma conta, ignorando-se a demonstração dos principais elementos desta abertura, a saber:

$\begin{array}{lcc} & \text { Custo dos Produtos Vendidos: } & \$ \\ & \text { Produtos e Serviços } & 371.145 \\ & \text { Despesas de Distribuição } & 2.475 \\ \ldots . & \text { Depreciações e Amortizações } & 62.552 \\ & \text { Total } & 436.172\end{array}$

O conteúdo informativo desta nota é absolutamente inexpressivo, porque o principal tem desta abertura, que representa $85 \%$ do total, continuou fechado sob a denominação "produtos e serviços", sem apresentação de seus principais componentes.

\section{Equivalência Patrimonial/Consolidação}

Outro aspecto interessante na análise das notas explicativas é aquele referente às informações sobre consolidação de balanço.

Uma das empresas "holding" puras (não apresentam vendas na demonstração de resultado) analisadas deixou de divulgar demonstrações consolidadas, pois os seus investimentos tinham a seguinte distribuição:

-> Investimentos em coligadas - $63 \%$ de seu Patrimônio Líquido

$\rightarrow \quad$ Investimentos em controladas - 19\% de seu Patrimônio Líquido

Apesar de ter $82 \%$ de seu Patrimônio representado por investimentos em outras companhias, segundo a Lei das S.A. somente deverá divulgar demonstrações consolidadas a companhia aberta que tiver mais de $30 \%$ do valor do seu Patrimônio Líquido representado por investimentos em sociedades controladas.

Entretanto, as demonstrações das empresas "holding" puras revelam-se extremamente pobres no que concerne ao seu conteúdo informativo, pois restringem-se a enormes valores em umas poucas linhas, como Investimentos e Patrimônio Líquido no balanço e Resultado de Equivalência Patrimonial na demonstração de 
Divulgação em Demonstrações Financeiras de Companhias Abertas 10

resultado, nada representando para o usuário tomar alguma decisão.

Especialmente neste caso, a alternativa seria a divulgação de maiores detalhes sobre as coligadas, talvez a publicação simultânea de um balanço e demonstração de resultado resumido da(s) investida(s).

Também constatamos empresas "holding" operacionais sem divulgação de demonstrações consolidadas. Uma delas apresentava aproximadamente 95\% de seu Patrimônio composto por investimentos distribuídos em controladas (2\%) e coligadas (93\%).

Para uma melhor visão desta distorção, vejamos alguns exemplos de demonstração de resultado de "holding" operacionais com "equity" relevante (pela correção integral):

\begin{tabular}{|l|c|c|c|c|}
\hline & $\begin{array}{c}\text { Renaux } \\
1989\end{array}$ & $\begin{array}{c}\text { Têxtil F. } \\
\text { Guimarães } \\
1989\end{array}$ & $\begin{array}{c}\text { Aracruz } \\
1990\end{array}$ & $\begin{array}{c}\text { Estrela } \\
1989\end{array}$ \\
\hline Receita Líquida & 526.391 & $\underline{611} 074$ & 38.137 .129 & 2.505 .168 \\
\hline Custo das Vendas & $\underline{(416.530)}$ & $(390.080)$ & $(18.852 .201)$ & 1.239 .843 \\
\hline Lucro Bruto & $\underline{109.861}$ & 220.994 & 19.284 .928 & 1.265 .325 \\
\hline Despesas Operacionais & 117.285 & $(204.573)$ & 19.696 .242 & 1.147 .339 \\
\hline Resultado antes da Equivalência & 7.424 & 16.421 & 411.314 & 117.986 \\
\hline Equivalência Patrimonial & & 100.860 & 624.816 & 110.112 \\
\hline Lucro Operacional & 56.742 & 117.281 & 213.502 & 228.098 \\
\hline Lucro Líquido & 49.318 & & 869.941 & 163.614 \\
\hline $\begin{array}{l}\text { Part. de invest. em controladas no Patrimônio } \\
\text { Líquido }\end{array}$ & $12 \%$ & $16 \%$ & $14 \%$ & $8 \%$ \\
\hline
\end{tabular}

No caso da Renaux, antes de ser apresentado o valor da equivalência patrimonial, ela gerou um prejuízo operacional da ordem de $\$ 7.400$ mil, tornando-se um lucro de $\$ 49.318$ mil após o "equity". Logo, o resultado de equivalência representa $115 \%$ do lucro operacional, ou $129 \%$ do lucro líquido ou, ainda, $52 \%$ do lucro bruto naquele período, percentuais esses bastante expressivos para serem explicados, ou melhor, para não serem explicados através de uma única linha da demonstração de resultado.

Em relação à Têxtil, constatamos um resultado de "equity" de $86 \%$ do lucro operacional, $106 \%$ do lucro líquido e $46 \%$ do lucro bruto. Percentuais significativos nestas relações também foram calculados para as demais empresas citadas.

Revela-se, assim, que algumas empresas abertas estão apresentando uma parcela significativa de geração de resultado através da "consolidação em uma linha", como também é denominado o resultado de equivalência patrimonial, quando na verdade deveria estar demonstrados pelos seus diversos componentes, como vendas, custo dos produtos vendido, etc. para possibilitar ao usuário uma análise de desempenho de melhor qualidade.

Acrescente-se a isto que a empresa controlada pode estar gerando um resultado cuja maior parte seja de origem não-operacional, enquanto a controladora divulga-o como operacional na linha de equivalência patrimonial.

Caderno de Estudos nº12, São Paulo, FIPECAFI, Setembro/1995 
Divulgação em Demonstrações Financeiras de Companhias Abertas 11

Percebe-se, desta maneira, a necessidade de uma maior flexibilidade em relação aos critérios legais, que deveriam prever a obrigatoriedade de consolidação em determinadas circunstâncias. como no caso em que o resultado líquido tivesse parcela significativa de efeito de resultado de investimentos em controladas, mesmo que esses investimentos em seu conjunto representassem menos de $30 \%$ do patrimônio líquido da controladora.

Ou, se este fato for apenas eventual, alguma outra forma melhor de informar

ao usuário, que não através de uma única linha na demonstração de resultado

\section{Prazo de divulgação}

Outro aspecto analisado foi o período para publicação das demonstrações financeiras. O menor prazo após a data-base do balanço foi de 23 dias, enquanto o maior constatado foi de 138 dias, sendo observados os seguintes intervalos:

- até 30 dias após data do balanço

- de31 a 60dias

- de 61 a 90 dias

- de 91 a 120 dias

- mais de 120 dias

$$
\begin{aligned}
& \text { - } 9 \text { publicações (70/o do total) } \\
& \text { - } 21 \text { publicações } \quad(15 \%) \\
& \text { - } 54 \text { publicações } \quad(40 \%) \\
& \text { - } 48 \text { publicações } \quad(36 \%) \\
& \text { - } 3 \text { publicações } \quad(2 \%)
\end{aligned}
$$

O dado mais surpreendente nesta pesquisa, sob nosso ponto-de-vista, foi no intervalo de 91 a 120 dias, com um total de 48 publicações, pois consideramos um período demasiado para fazer chegar ao usuário as informações sobre o desempenho de uma empresa.

Entendemos que deveria ser definido um prazo menor para a divulgação das demonstrações financeiras, posto que não se justifica que seja feita em prazo superior a 60 dias após a data do balanço, já que perde em muito sua essência de auxiliar o tomador de decisão, especialmente nos dias atuais, em que as decisões precisam ser tomadas rapidamente.

\section{Conclusão}

A evidenciação de informações de natureza contábil / financeira por parte das companhias abertas apresentou uma real evolução no Brasil, particularmente a partir de 1972. Entretanto, ainda há um longo caminho a percorrer no sentido de tomar o conjunto das demonstrações financeiras, no qual concluímos deva ser inserido o Relatório da Administração, uma peça harmoniosa em termos do inter-relacionamento entre os números demonstrados e os comentários elaborados no sentido de justificar decisões tomadas ao longo de determinado período.

Foi possível constatar neste trabalho o grau satisfatório de nossa regulamentação, apesar de ainda necessitarmos alguns aperfeiçoamentos.

Como resultado, apresentamos em seguida algumas sugestões, que entendemos necessárias, no sentido de atingirmos o objetivo da divulgação.

- auditoria formal por parte dos auditores independentes, das informações divulgadas no Relatório da Administração, o qual passaria a integrar o conjunto de informações financeiras, com conseqüente menção no Parecer dos auditores externos

- desvinculação das técnicas contábeis do corpo da legislação societária, dando-lhes maior flexibilidade para acompanhar a evolução do processo econômico;

Caderno de Estudos nº12, São Paulo, FIPECAFI, Setembro/1995 
Divulgação em Demonstrações Financeiras de Companhias Abertas 12

- como conseqüência desta desvinculação, a criação de um órgão normativo contábil;

- na demonstração de resultado, a abertura do grupo Custo dos Produtos Vendidos, pelos seus principais componentes, assim como as Despesas de Vendas e Administrativas, além do destaque das despesas com Pesquisa e Desenvolvimento;

- apresentação das demonstrações financeiras somente em moeda de poder aquisitivo constante;

- desvinculação entre conceitos contábeis e fiscais, com controle fiscal em registro específico;

- redução no prazo legal para divulgação das demonstrações financeiras.

- maior ênfase no Relatório da Administração aos planos dos administradores para o(s) exercício(s) seguinte(s), com a clara descrição do cenário econômico considerado,

- utilização das Notas Explicativas para informações relevantes em termos de propiciar melhor qualidade de análise, tais como:

a. prazos médios de pagamentos/recebimentos;

b. taxas de juros reais obtidas/pagas;

c. rotação dos principais grupos de estoques,

d. principais índices econômico-financeiros;

e. demonstração da movimentação do imobilizado, investimentos e diferido;

f. conciliação entre o resultado contábil e aquele apurado para efeito de tributação, com indicação da natureza dos principais itens divergentes e o período pelo qual deverão perdurar;

g. valor de mercado dos estoques e dos investimentos temporários;

h. divulgação dos honorários pagos aos auditores independentes;

i. informações sobre proteção ao meio ambiente;

j. divulgação adequada de "off-balance-sheet";

k. explicações sobre variações relevantes nos saldos das principais contas de balanço ou resultado:

I. indicação de concessão de subsídios governamentais, sua natureza, destinação, valor e prazos.

- substituição da demonstração de origens e aplicações de recursos pela de fluxo de caixa;

- obrigatoriedade das demonstrações de valor adicionado e por segmento econômico;

Caderno de Estudos nº12, São Paulo, FIPECAFI, Setembro/1995 
- adequada evidenciação para as empresas prestadoras de serviços em termos de seu nível de atividades, tal como horas/homem trabalhadas por principais ramos de negócios;

- a comparabilidade deveria ser feita para pelo menos três exercícios sociais;

- diferimento do pagamento da parcela de dividendo mínimo incidente sobre o resultado líquido positivo da equivalência patrimonial, até o exercício do efetivo recebimento do dividendo relativo a este resultado, alienação do investimento ou capitalização de lucros e reservas correspondentes por parte da controlada ou coligada, ficando clara a necessidade da disponibilidade de recurso financeiro para o pagamento do dividendo, o que se dá somente quando os dividendos são pagos pela empresa coligada ou controlada e não em razão do lucro trazido para a conta de resultado da empresa controladora através do método de equivalência patrimonial. 